\title{
Os debates sobre a mineração no bioma Pampa: conflitos socioambientais em meio a projetos locais de vida
}

\section{The debates about mining in the Pampa biome: socio-environmental conflicts amidst local life projects}

Sérgio Botton Barcellos - Professor adjunto na área de Sociologia do Instituto de Ciências Humanas e da Informação (ICHI) na Universidade Federal do Rio Grande (FURG). Docente no Programa de Pós-Graduação em Sociologia da Universidade Federal de Pelotas (UFPel) e Educação Ambiental da Universidade Federal do Rio Grande (FURG). E-mail: .sergiobbarcellos@hotmail.com

Daniel Vaz Lima - Doutorando em Antropologia no Programa de Pós-Graduação em Antropologia da Universidade Federal de Pelotas (PPGAnt/UFPel). Mestre em antropologia pelo mesmo programa.E-mail: dvlima.vaz@gmail.com

Patrícia dos Santos Pinheiro - Doutora em Ciências Sociais pelo Programa de PósGraduação de Ciências Sociais em Desenvolvimento, Agricultura e Sociedade (CPDA/ UFRRJ). Realiza pós-doutorado no Programa de Pós-Graduação em Antropologia na Universidade Federal da Paraíba (bolsista PNPD Capes). Fez pós-doutorado pelo Programa de Pós-Graduação em Antropologia (PPGAnt/UFPEL), com bolsa Fapergs/ Docfix. E-mail: patriciasantspinheiro@gmail.com

\section{Resumo}

Os projetos em mineração estão em expansão no Brasil e também no Rio Grande do Sul, incluindo a denominada "metade sul", no bioma Pampa. A possibilidade da instalação de uma mina em Caçapava do Sul/RS está gerando impasses entre empresa, pesquisadores e grupos locais. A partir deste trabalho, analisaremos como se configuram os acordos e conflitos nos debates públicos sobre a implantação dos projetos em mineração no bioma Pampa. Com metodologia qualitativa, o foco se dará no debate público sobre a mineração em jornais, redes sociais e audiências públicas, por agregarem diferentes aspectos socioculturais e político-ideológicos. O escopo teórico inclui os conceitos de configuração e processo de longa duração em Norbert Elias e de arenas públicas (CEFAÏ, 2009), assim como a bibliografia sobre conflitos socioambientais. A partir desse estudo, foi possível discutir as relações de acordo e disputa nesse debate e refletir sobre a configuração contemporânea dos conflitos socioambientais no contexto rural brasileiro.

\section{Palavras-chave}

Mineração. Bioma Pampa. Conflitos Socioambientais.

\begin{abstract}
Mining projects are expanding in Brazil and also in Rio Grande do Sul, including the so-called "southern half" in the Pampa biome. The possibility of installation a mine in Caçapava do Sul / RS is generating impasses between companies, researchers and local groups. From this work, we will analyze how the agreements and conflicts are configured in public debates about the implementation of mining projects in the Pampa biome. As of qualitative methodology, the focus will be on the public debate about mining in newspapers, social networks and public audiences, for adding different socio-cultural and politicalideological aspects. The theoretical scope includes the concepts of long-duration configuration and process in Norbert Elias and public arenas (CEFAÏ, 2009), as well as the bibliography on socio-environmental conflicts. From this study, it was possible to discuss the relations of agreement and dispute in this debate and to reflect on the contemporary configuration of the socioenvironmental conflicts in the Brazilian rural context.
\end{abstract}

\section{Keywords}

Mining. Bioma Pampa. South half RS. Socioenvironmental conflicts. 


\section{INTRODUÇÃO}

As empresas mineradoras, que pleiteiam a expansão da sua atuação em diferentes partes do Brasil, também se encontram no Rio Grande do Sul (RS), sendo que um caso emblemático está ocorrendo na denominada "metade sul" ou "região da Campanha" no bioma Pampa. Os empreendimentos que buscam se instalar nesta região têm como área de influência o conjunto dos municípios que compõem a bacia hidrográfica do rio Camaquã até o seu deságue junto à lagoa dos Patos e no oceano Atlântico, no município de Rio Grande, extremo sul do Brasil. As atividades de mineração em questão incluem a extração de minerais, como cobre, fosfato, prata, ouro, zinco e a extração de chumbo.

Analisando esta questão sob um contexto mais amplo, em uma certa reedição de práticas instituídas desde o período colonial no Brasil, permanece uma estreita relação entre a extração de recursos naturais e a conformação mercantil. E assim como ocorre com a maior parte dos recursos naturais extraídos, convertidos em commodities, também os minérios abastecem largamente o mercado externo. Com relevância crescente na base econômica nacional, no ano 2000, por exemplo, os empreendimentos em mineração obtiveram crescimento de $8,2 \%$, sendo o setor que individualmente obteve o maior crescimento no Produto Interno Bruto (PIB) (BARRETO, 2001). Segundo Malerba, Milanez e Wanderley (2012), de 2000 a 2011, a participação da indústria mineradora no PIB aumentou de 1,6 para 4,1\%. Ainda, de acordo com o Plano Nacional de Mineração 2030 (PNM 2030) do Ministério de Minas e Energia (MME), em 2013 o percentual de participação da mineração no PIB chegou a 4,2\%, representando $20 \%$ do total das exportações ${ }^{1}$.

Os principais produtos minerais metálicos exportados pelo Brasil são minério de ferro, alumínio, ouro e cobre. O minério de ferro respondeu, em 2009, por $63,5 \%$ das exportações brasileiras de minérios, que chegaram a quase US $\$ 20$ bilhões. O segundo produto mineral exportado foi o alumínio (US\$3 bilhões), após ouro (US $\$ 1,43$ bilhão), cobre (US $\$ 1,4$ bilhão) e as rochas ornamentais (minério não metálico) com 2,2\% do total das exportações). São também importantes produtos de exportação, embora com menor peso: chumbo, manganês, estanho, caulim, diamantes, pedras preciosas, amianto e magnesita (MME, 2013). Além disso, há um grande potencial geológico brasileiro não explorado, e, como pode

1 O aumento da demanda de minério ocorre pela expansão da fabricação de microeletrônicos e a realização de obras de infraestrutura e habitação nos países considerados emergentes nesse estágio global do capitalismo. Além disso, percebe-se o crescimento acelerado da demanda de ouro por parte da China, o que estimulou o aumento da cotação dos metais, somado ao enfraquecimento do dólar, o que, por sua vez está gerando uma maior procura por metais como reserva financeira. 
ser visto pelo Plano Nacional de Mineração 2030: é forte o estímulo à atividade de mineração. Segundo este Plano, há previsão de investimentos de R $\$ 350$ bilhões até 2030, destinados prioritariamente à Amazônia, mas também a outros locais. De todo modo, trata-se de um indicativo de que poderá se intensificar a atividade extrativa no país como um todo.

Além de inúmeros casos de impactos negativos desta atividade na América Latina e na África, os riscos socioambientais em torno da mineração têm crescido em face das pressões por lucratividade, aliadas ao financiamento público. De acordo com o Observatório dos Conflitos em Mineração da América Latina (OCMAL) ${ }^{2}$ registram-se 229 projetos de mineração implicados em conflitos socioambientais e 334 comunidades afetadas por esses projetos. No Brasil, de acordo com o Mapeamento dos Conflitos Ambientais, dos 577 conflitos socioambientais que estão ocorrendo no Brasil, cerca de 80 são conflitos oriundos de projetos e áreas de mineração, garimpos e siderurgia no Brasil.

Para Almeida (2012, p. 63), está em jogo um reordenamento territorial, operado também pelo Estado brasileiro, "voltado para a reestruturação de mercados, disciplinando a comercialização da terra e dos recursos florestais e do subsolo", expresso em incentivos e flexibilizações de leis de proteção ambiental e social em curso. Trata-se, segundo o autor, não mais de proteção (em sentido conservacionista), mas sim, em direção diametralmente oposta (mesmo que não haja alterações retóricas profundas), de "protecionismo", calcado na possibilidade de intensificação do uso de recursos naturais a partir daquilo que é indicado como potencial de crescimento econômico. Nesse processo, vemos empreendimentos hidrelétricos, portuários, projetos de mineração, entre outros, multiplicaremse pelo Brasil, apontados como solução para regiões "pobres". Em suma, o protecionismo seria direcionado não aos elementos naturais, mas sim à economia.

No Rio Grande do Sul, após um ciclo intenso de atividades de silvicultura altamente impactantes para o bioma Pampa, ainda não findado, os empreendimentos em mineração surgem como a mais nova promessa de "desenvolvimento econômico" e "emprego", com a proposta de "dinamizar" a matriz econômica desta região, histórica e culturalmente agropastoril. Atualmente a possibilidade da instalação de um empreendimento entre os municípios de Caçapava do Sul e Santana da Boa Vista está gerando impasses entre empresa/ pesquisadores/comunidade local ${ }^{3}$ em debates e audiências públicas, assim como ações junto ao Ministério Público Federal (MPF).

Ler mais em: http://basedatos.conflictosmineros.net/ocmal_db/

Entende-se como comunidade: pequenos, médios e grandes produtores pecuários e agrícolas, quilombolas, indígenas e comunidades nos municípios. 
Diante desse contexto, neste trabalho ${ }^{4}$ temos a seguinte questão central: como se configuram os acordos, as disputas e os conflitos nos debates públicos sobre a implantação dos empreendimentos em mineração no bioma Pampa no Rio Grande do Sul? Procuramos, assim, compreender, neste universo de pesquisa, as imbricadas e dinâmicas relações que têm se conformado em arenas públicas formadas a partir do conflito entorno da instalação de empreendimentos de mineração em municípios do bioma Pampa. A partir daí são analisadas as reivindicações e as mobilizações dos atores sociais que configuram as controvérsias acerca da mineração no universo de pesquisa tendo como referências a teorização das configurações de Norbert Elias e a perspectiva de arenas públicas em Daniel Cefai. Além destes, contaremos com o aporte teórico sobre a temática dos conflitos socioambientais e da justiça ambiental como Acselrad (2010), Zhouri (2010), Leite Lopes (2006) etc. entre outros.

A metodologia a ser trabalhada é qualitativa e os procedimentos de pesquisa utilizados foram a observação direta em três audiências públicas em três municípios do Rio Grande do Sul, Santana da Boa Vista, Bagé e Pinheiro Machado, promovidas pela Fundação Estadual de Proteção Ambiental Henrique Luiz Roessler - RS (Fepam) e a empresa Votorantim ao longo de 2016 e em três audiências públicas de iniciativa do poder legislativo, uma delas na Assembleia Legislativa do Rio Grande do Sul (Alergs) e outras duas nas câmaras municipais de Pelotas e Rio Grande no ano de 2017. Além disso, realizamos coleta de depoimentos nessas audiências e em redes sociais como páginas no Facebook, e em sites e jornais regionais ${ }^{5}$.

Ao discutir as aproximações e os distanciamentos entre os atores nos debates públicos sobre a instalação desse empreendimento em mineração no bioma Pampa, procuraremos também conectar essa reflexão com a configuração das várias formas de conflitos socioambientais na atualidade do contexto brasileiro. Dessa forma, na primeira parte deste trabalho descreveremos o bioma Pampa e as questões atinentes ao desenvolvimento da atividade mineradora no Brasil nessa região do estado do Rio Grande do Sul. Na segunda parte trataremos da configuração das relações de conflitos, disputas e acordo entre os atores que são favoráveis e contrários ao longo do processo de tentativa de implantação do "Projeto Caçapava do Sul” que está em fase de análise junto à Fepam-RS.

Este trabalho teve uma versão preliminar apresentada no XVIII Congresso da Sociedade Brasileira de Sociologia (SBS) em julho de 2017, em Brasília.

5 Coletamos depoimentos na página "União pelo Camaquã", "Projeto Caçapava Do Sul - Eu Apoio", Jornal Sul21, Diário Popular e Jornal Minuano. 


\section{O BIOMA PAMPA E A QUESTÃO DA MINERAÇÃO}

O bioma Pampa é constituído principalmente por vegetação campestre. $\mathrm{O}$ mesmo abrange Uruguai, Brasil e Argentina, em uma área de aproximadamente 750 mil km². No Brasil, esse bioma foi delimitado pelo Instituto Brasileiro de Geografia e Estatística (IBGE) apenas em 2004, junto com os demais biomas brasileiros. Também indicado como Campo Sulino, representa 63\% da área do Rio Grande do Sul, com quase 180 mil km² e abriga parcialmente o aquífero Guarani. Apesar de uma aparente homogeneidade da vegetação de campos nativos, apresenta uma vasta biodiversidade entre serras, planícies e coxilhas, com gramíneas, formações arbustivas, banhados, capões de matas, butiazais etc.

De acordo com o Ministério do Meio Ambiente (MMA), em 2017, estimase que existiam cerca de 500 espécies de aves, 100 de mamíferos e 3.000 espécies de plantas, com diversas espécies endêmicas de fauna e flora, nem todas descritas ainda. Tal biodiversidade de espécies de flora pode ser observada na consideração de que um metro quadrado de campo nativo pode conter mais de 50 espécies diferentes de plantas tornando essas pastagens naturais adequadas ao pastoreio.

A pecuária extensiva sobre os campos nativos tem sido uma importante atividade econômica da região, desenvolvida não somente em grandes estâncias, mas principalmente em pequenas e médias propriedades. Destaca-se que os pecuaristas familiares, grupo social que compõe os produtores de gado, também configuraram sua identidade no contex to histórico de ocupação do Pampa, a partir de três principais características: processos de sucessão rural por fracionamento de terras das grandes estâncias; compra de terras por agricultores familiares que migraram de regiões de colonização e a compra da terra pelos trabalhadores das estâncias (FERNANDES; MIGUEL, 2016) ${ }^{6}$.

A sua presença, de modo geral, transformou o Pampa, considerando que os herbívoros bovinos, equinos e ovinos contiveram o avanço da "vegetação lenhosa" sobre essas áreas campestres (BENCKE, 2016). No entanto, cabe ressaltar que a matriz produtiva histórica vinculada a esta atividade se diferencia do arranjo produtivo praticado atualmente por pecuaristas no Centro-Oeste e no Norte do Brasil, onde ocorre a derrubada de florestas e plantio de gramíneas para alimentação do rebanho, em geral em grandes propriedades (CANCELIER; KASSOL; NET'TO, 2017).

6 De acordo com Cancelier, Kassol e Netto (2017), são considerados pecuaristas familiares os produtores que têm como atividade predominante a (re)criação de bovinos, caprinos, bubalinos e ovinos com a finalidade de corte e utilizem trabalho familiar, em alguns casos com mão de obra contratada sazonalmente; deter a posse, a qualquer título, de estabelecimento rural com área total inferior a 300 hectares com residência nele ou em local próximo a ele; e obtenham no mínimo $70 \%$ da sua renda da atividade pecuária e não agropecuária do estabelecimento, fora benefícios sociais e aposentadorias. 
Vivendo em pequenas propriedades os pecuaristas familiares têm como atividade principal, a criação de animais bovinos, ovinos e caprinos manejando tais rebanhos com mão-de-obra familiar, eventualmente, contratando mão-deobra externa ou trocando serviços entre os vizinhos. Além disso, cultivam cereais tais como o milho, que é destinado tanto a alimentação humana quanto dos outros animais, e o feijão. Possuem hortas para o consumo de verduras e legumes e também pomares (denominadas de "quintas") em que produzem frutas para fazer doces tanto para o autoconsumo como para a venda nas feiras. O cotidiano das famílias está relacionado ao manejo dos animais como, por exemplo, no início da manhã e no final da tarde é o momento em que os animais estão próximos às casas e assim, recebem ração, e as vacas são ordenhadas. Na região do Alto Camaquã alguns pecuaristas familiares estão organizados em pequenas associações que promovem cursos de capacitação para manejos de animais, de pasto etc. As associações também possuem estruturas coletivas como o banheiro de imersão para bovinos já que os associados não possuem o número suficiente de animais para viabilizar a compra de carrapaticidas.

No Pampa convivem, além de agricultores e pecuaristas, comunidades quilombolas ${ }^{7}$, pescadores artesanais, povo cigano, de terreiro e pomerano. Estes grupos sociais desenvolveram importantes conhecimentos associados ao valor alimentar, medicinal etc. das espécies presentes no Pampa, as quais compõem importante patrimônio cultural. Entretanto, o contexto de tais territórios está marcado pelo avanço de modelos de desenvolvimento com potenciais de transformações radicais nestas paisagens e biodiversidade (MAZURANA; DIAS; LAUREANO, 2016).

A partir dos anos 2000 na metade sul do Rio Grande do Sul, a região passou a ser alvo de novas investidas de grandes empreendimentos na busca de um almejado crescimento econômico de uma área considerada a parte menos "desenvolvida" do estado. Assim, os cultivos de soja e milho transgênicos se propagaram sobre os campos nativos, ocasionando a multiplicação de espécies exóticas, tais como o capim-anoni, há lavouras de silvicultura (especialmente com eucaliptos, pinus e acácia negra) e, mais recentemente, as atividades em mineração estão na ordem do dia. Em relação aos cultivos agropecuários, estas atividades se pautam na agricultura considerada "convencional" (com uso intenso de insumos e tecnologias externas), especialmente a sojicultura, atividades estas estimuladas por sucessivos governos de estado no Rio Grande do Sul e prefeituras na região, bem como por empresas ligadas ao agronegócio, que expandiram sua fronteira agrícola na metade sul do estado.

Atualmente no bioma Pampa encontram-se 92 quilombos certificados pela Fundação Cultural Palmares. 
Destaca-se que a perda de biodiversidade compromete o bioma, que já é o segundo mais alterado do Brasil, com apenas 36\% de cobertura original (MMA, 2017), o que pode levar à perda de espécies de fauna e flora, ao aumento da erosão do solo e do processo de arenização, assim como possíveis mudanças climáticas. No que tange ao aspecto socioambiental, Acselrad (2004) descreveu que dois processos caracterizaram a territorialidade do capitalismo brasileiro, sendo que o primeiro diz respeito à concentração crescente do controle dos recursos naturais por poucos atores e a acumulação capitalista, que faz uso de escalas cada vez mais amplas de produção, de avanços sobre novos espaços sociais para a exploração do trabalho e de especulação fundiária. O segundo processo na construção desta territorialidade foi à privatização do uso de espaços com recursos naturais de uso comum, mais especificamente das águas e de minerais, com a reprodução de um modelo da sociedade capitalista moderna e com a intensificação da produção do trabalho no ambiente (ACSELRAD, 2004).

Um importante estímulo governamental para a formação dessa territorialidade capitalista ocorreu no ano de 2005, quando o governador do estado, Germano Rigotto, decidiu promover o "Projeto Losango", voltado para a produção de silvicultura em forma de monocultura como mais uma ideia para o crescimento econômico do Pampa gaúcho. Do ponto de vista socioeconômico, o objetivo seria transformar a matriz econômica do Pampa, que é histórica e culturalmente pastoril, em uma região de produção de madeira e celulose.

Nessa última década também foi observado nessa região, identificada geologicamente como Escudo Sul-Riograndense, o interesse pelas reservas de metal precioso, desde as jazidas já conhecidas e os antigos garimpos, até novas áreas com potencial, em municípios como Caçapava do Sul, Encruzilhada do Sul, Lavras do Sul, Santana da Boa Vista, São Sepé e Pinheiro Machado. Nestes municípios algumas áreas vêm sendo alvo, desde 2008, de um intenso trabalho de pesquisa geológica para detectar pontos promissores, ampliar as reservas existentes e viabilizar projetos de extração mineral. Exemplo disso são os dados do Departamento Nacional de Produção Mineral (DNPM) - que passará a ser a Agência Nacional de Mineração (ANM) ${ }^{9}$. Consta que há um cadastro de 162 processos ativos de prospecção para busca de ouro, chumbo, cobre, prata e zinco na região do Bioma Pampa (Figura 1).

8 Essa política pública estimulada por grandes empresas de produção de celulose e assumida pelo governo do RS na época dividia o estado em três áreas geridas por grandes empresas: a Aracruz (na Depressão Central e região de Porto Alegre), a Votorantim (na região do entorno e retaguarda das cidades de Pelotas e Rio Grande) e a Stora Enso (na fronteira sudoeste).

9 Essa mudança de caráter institucional faz parte de um programa de revitalização da atividade mineradora estimulado pelo governo federal - responsável pela concessão de alvarás para o estudo de áreas e fiscalização de empresas, segundo o Portal Planalto (2017). 
Figura 1 - Mapa com os projetos de mineração no Rio Grande do Sul

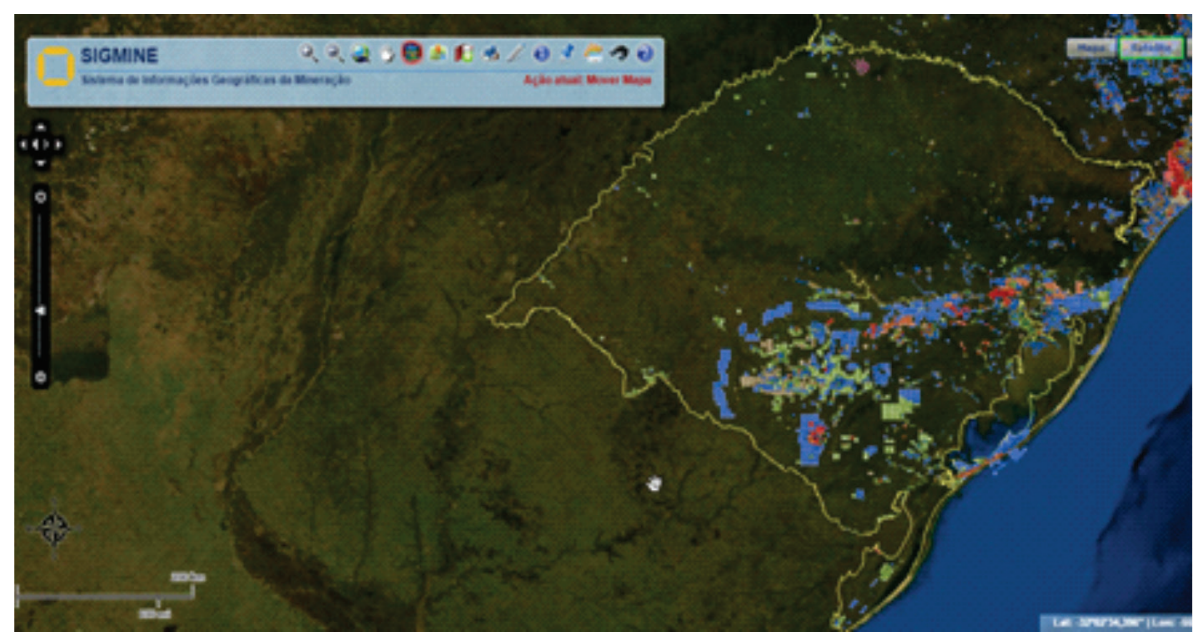

Fonte: Site DNPM (2017)

Em um período mais recente, em meados do ano de 2016, a Votorantim Metais Holding protocolou um EIA-RIMA (Estudo e Relatório de Impacto Ambiental) na Fepam-RS e fez duas audiências públicas para apresentar o projeto à população. Consta no EIA do empreendimento (2016) que a companhia propositora tem feito pesquisas no local desde 2008 e teria confirmado a viabilidade econômica da extração de metais ${ }^{10}$. Segundo o seu site, neste projeto consta a intenção de exploração de zinco, cobre, chumbo, além de prata como subproduto, no Passo do Cação, localidade a cerca de cinco quilômetros de Minas do Camaquã ${ }^{11}$ e que terá uma das minas há cerca de $800 \mathrm{~m}$ do rio Camaquã. A proposta é exportar concentrados dos minérios pelo porto de Rio Grande para mercados internacionais como a Europa e a China, ou ainda aproveitar alguns deles nas metalúrgicas da Votorantim Metais em Minas Gerais (caso do zinco).

As audiências públicas, que são atividades condicionantes para a implementação do empreendimento, ocorreram na Vila de Minas do Camaquã, município de Caçapava do Sul, e na própria sede do município, em julho de 2016. Os municípios de Santana da Boa Vista, Bagé e Pinheiro Machado foram excluídos da consulta pela Fepam, apesar de os três fazerem limite com a localidade do empreendimento e apresentarem potenciais impactos em função do projeto. Após o protesto de grupos comunitários nos municípios e com a

10 Ler mais em: Diário de Santa Maria. Votorantim pesquisa zinco. Mineradora trabalha para encontrar reservas. Santa Maria, 20 mar. 2010. Disponível em: http://www.clicrbs.com.br/ dsm/rs/impressa/4,40,2843820,14335. Acesso em: 07 jan. 2017.

11 O local já recebeu outras minas há mais de 50 anos, como será exposto a seguir. 
intervenção do Ministério Público Federal (MPF), novas audiências foram promovidas pela Fundação. Foram organizadas, então, audiências públicas em Santana da Boa Vista, Bagé e Pinheiro Machado, onde a mineradora também apresentou detalhes e prestou mais informações sobre o EIA-RIMA ${ }^{12}$. Logo em seguida, com a difusão das informações sobre o projeto, os planos da empresa geraram polêmicas em grande parte dos 28 municípios que compõem a Bacia Hidrográfica do Rio Camaquã, que é o principal curso d'água na região.

Essa bacia hidrográfica abrange uma área de cerca de $21.657 \mathrm{~km}^{2}$ e o rio principal tem uma extensão aproximada de $430 \mathrm{~km}$. A nascente do rio é a oeste da bacia, onde é formado pelos principais afluentes de Lavras do Sul, Hilário e Camaquã Chico e sua jusante é na Laguna dos Patos, entre os municípios de São Lourenço do Sul e Camaquã (Figura 2).

Figura 2 - Bacia hidrográfica do rio Camaquã

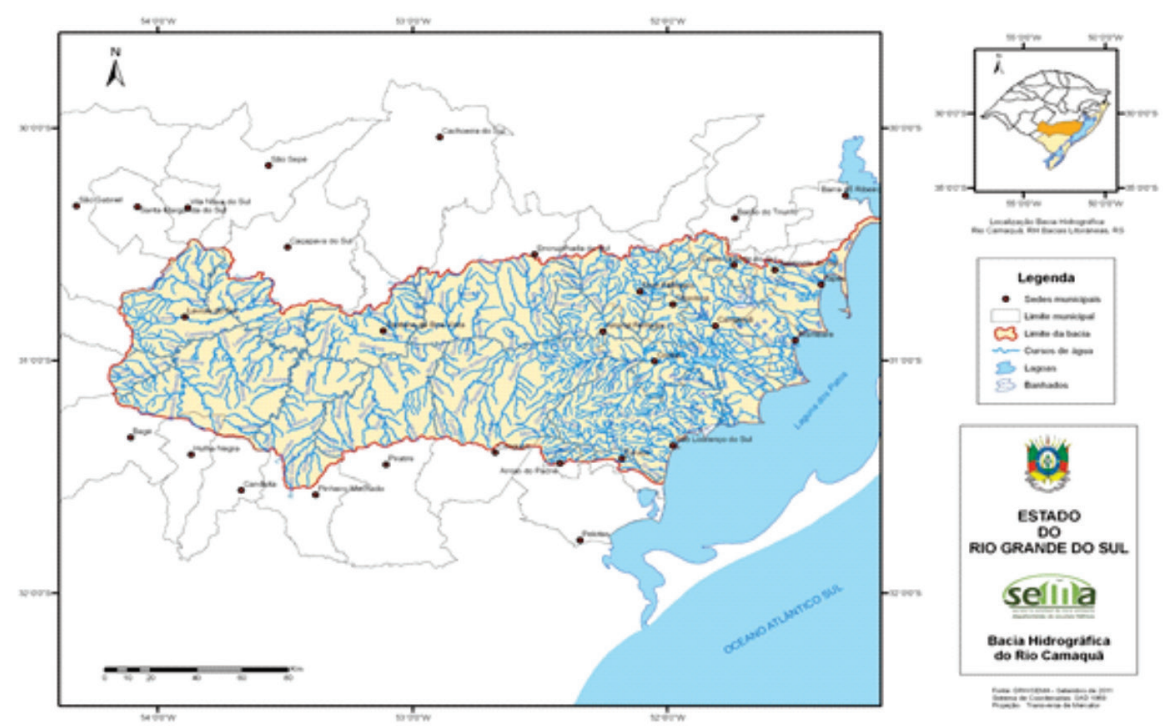

Fonte: Comitê de Gerenciamento da Bacia Hidrográfica do Rio Camaquã

A empresa mineradora prevê um investimento inicial de $\mathrm{R} \$ 371$ milhões e anuncia que irá gerar 450 empregos diretos com a instalação do empreendimento, com potencial de geração de empregos indiretos. O projeto apresenta a expectativa de iniciar suas operações no primeiro trimestre de 2020. A extração das lavras que serão a céu aberto prevê a produção anual de 16 mil toneladas de zinco concentrado, 5 mil de cobre e 36 mil de chumbo durante 20 anos. A empresa divulga que não utilizará barragem de rejeitos líquidos.

12 As apresentações estão disponíveis no site da empresa: http:/www.projetocacapavadosul.com.br/. 
Por outro lado, grupos organizados e atores da sociedade civil (associações, prefeituras, grupos auto organizados e professores universitários), que descreveremos de forma mais detalhada a seguir, são contrários à instalação do empreendimento na região. Além da possível contaminação do rio Camaquã, do solo, da flora e fauna da região, em especial pelo concentrado de chumbo, estas organizações ponderam que se houvesse um investimento maior na ovinocultura - a região possui mais de 650 mil cabeças de ovinos - seria possível arrecadar mais de R\$120 milhões. Eles também denunciam que a grande geração de empregos prometida com a instalação desses empreendimentos se dará fora da região, pois os minérios serão exportados na forma bruta. Ou seja, segundo estas críticas, a justificativa do empreendimento se instalar na região não seria nem econômica, nem social ou ambiental, apenas voltada aos interesses da empresa.

Além disso, pelo Porto de Rio Grande se projeta o escoamento do concentrado de minérios metálicos, inclusive o metal pesado chumbo, com alta capacidade de contaminação, município que não foi consultado ou ao menos informado antes da audiência pública promovida em junho de 2017 $7^{13}$, sobre a possibilidade da instalação desse empreendimento oferecer riscos de contaminação a população e ao ambiente pela aspersão de partículas de minérios no ar e na água. Destaca-se que diversos municípios que compõem a bacia hidrográfica do rio Camaquã também não foram consultados ou informados dos riscos socioambientais que esse empreendimento oferece, seja pela possibilidade de contaminar as águas do rio Camaquã, seja pela aspersão de partículas pelo trajeto dos caminhões que transportarão os concentrados até o Porto de Rio Grande ${ }^{14}$.

Sob essa perspectiva, em acordo com Zhouri e Laschefski (2010), também entendemos que as situações consideradas como "problemas ambientais" originadas pelo "desenvolvimento" podem ser compreendidas pela noção de conflito ambiental. O caráter conflituoso é relativo à forma como objetivamente são configuradas as relações entre os grupos com posições distintas, sobre pretensões de uso e significados atribuídos a um mesmo território em disputa e que são ecologicamente interconectados. Para Zhouri e Laschefski (2010) os conflitos socioambientais têm em seu gérmen as formas distintas de existência

13 Audiência promovida pela Câmara de Vereadores de Rio Grande através do mandato da Vereadora Denise com apoio de docente da FURG - Campus Carreiros. Disponível em: https://www.youtube.com/watch?v=FWSSmq31xb4

14 Cabe, ainda, destacar que o Porto do Rio Grande é a porta de saída desses processos de mineração em prospecção ou licenciados, como é o caso da exploração de zircônio e titânio pela Rio Grande Mineração, no município de São José do Norte, que recentemente recebeu o aval do IBAMA para começar sua instalação, mesmo com a comunidade se manifestando de forma contrária. 
em que disputam o sentido do conceito de desenvolvimento, e demonstram a luta por autonomia de grupos, organizações e movimentos sociais que resistem aos modelos de sociedade impostos, por exemplo, nos empreendimentos transnacionais que se instalam no Brasil sem consultar as comunidades locais.

Para Acselrad e Da Silva (2011), os projetos desenvolvimentistas, neste caso a atividade mineradora, alteram radicalmente espaços físicos regionais, seus respectivos ecossistemas terrestres e aquáticos, bem como as redes de relações sociais sobre as bases espaciais até então prevalecentes. Os autores indicam que esta alteração das relações sociais será maior de acordo com a intensidade que às populações das áreas de implantação destes empreendimentos tiverem suas condições de existência e suas estratégias de trabalho associadas estreitamente ao ambiente físico e ao meio biótico locais. Assim, trabalho, terra e recursos naturais serão incorporados em formas sociais distintas das precedentes à medida que estes projetos intervenham no espaço.

Mediante este conflito de interesses e de projetos para a região, o EIARIMA apresentado pela empresa foi analisado com mais profundidade pela Fepam em novembro de 2016, época em que os grupos contrários ao empreendimento haviam realizado moções de repúdio e foram instaurados inquéritos nos ministérios públicos estadual e federal, reivindicando esclarecimentos sobre o processo junto à fundação. Em janeiro de 2017, a Fepam concluiu parecer técnico com a análise do EIA-RIMA em que questiona a mineradora sobre diversos pontos, desde a descrição do empreendimento até complementações sobre o inventário feito na fauna da região. A empresa solicitou um prazo para organizar o cronograma de ações para se adequar às exigências e até fevereiro de 2018 haverá uma resposta da Fepam.

Diante desse impasse relativo à implementação do empreendimento, "os conflitos ambientais surgem das distintas práticas de apropriação técnica, social e cultural do mundo material" (ZHOURI; LASCHEFSKI, 2010, p. 17). Ao mesmo tempo, sob uma perspectiva mais ampla, podemos compreender esse conflito em meio a um cenário marcado por políticas econômicas de ajuste fiscal e pela formação de superávits comerciais, no qual os instrumentos normativos de regulação ambiental estão no cerne de uma disputa. Essa questão posiciona, de um lado, aqueles que consideram os trâmites e as consultas às comunidades como "obstáculos ao desenvolvimento" e, de outro, os atores que querem participar das decisões sobre os territórios onde vivem e constroem os seus projetos de vida.

Diante desse contexto, a seguir iremos problematizar a configuração das relações de acordo, disputa e os conflitos socioambientais em jogo no debate sobre a mineração e os possíveis impactos nessa região. 


\section{CONFIGURAÇÕES DE DISPUTASECONFLITOSEM MINERAÇÃO NO BIOMA PAMPA}

Embora presente em outros momentos da história da humanidade e de diferentes maneiras, as preocupações contemporâneas com a questão ambiental, problematizadas por diferentes olhares, no contexto atual assumem uma visibilidade diferenciada. Seja em um deslocamento discursivo, seja na adoção da questão ambiental enquanto vinculada a determinadas possibilidades práticas, justificando-as e estimulando-as, esse movimento, que alguns autores se referem como ambientalização (LEITE LOPES, 2006), carrega uma historicidade que abrange a diversidade de grupos sociais e formas possíveis de participação na sua construção enquanto questão social, sem eximir a presença de muitas contradições e disputas entre perspectivas. De tal diversidade de situações resultam, evidentemente, inúmeras formas de apropriação e reelaboração da questão ambiental, tanto no comportamento da chamada sociedade civil quanto de ações e legislações estatais.

Leite Lopes argumenta que, em um processo de ambientalização e busca por legitimidade, há movimentos mais recentes de mudanças junto ao próprio polo "degradador", quando os grandes empreendedores, considerados os principais causadores de danos ambientais, procuram se apropriar desse processo em uma reconfiguração de sua imagem, usando-a como forma de positivação, mesmo que apenas em um plano discursivo (LEITE LOPES, 2006). Com isso, Leite Lopes avalia que na interiorização da questão ambiental, há tanto o processo de manutenção de ações de acumulação primitiva ambiental, apesar de mudanças discursivas operadas quanto o dessa "violência doce do uso da linguagem e procedimentos ambientalmente corretos no contexto da dominação empresarial exercida de forma socialmente irresponsável” (LEITE LOPES, 2006, p. 32).

Por outro lado, há um debate consolidado sobre situações de injustiça ambiental, configurando uma diversificada presença de justificativas nesse processo. Nessa perspectiva, há setores, como os movimentos populares que têm se mobilizado a partir das lutas ambientais, analisados por Acselrad (2010), que chamam a atenção para uma forte relação entre risco ambiental e insegurança social, tornando essas lutas mais amplas:

Torna-se assim também crescentemente difundido o entendimento de que a proteção ambiental não é, ao contrário do senso comum, causa restrita a classes médias urbanas, mas parte integrante das lutas sociais das maiorias. E é por meio de suas estratégias argumentativas e formas 
de luta inovadoras que os atores sociais, cuja práticas aqui analisamos, têm procurado, no Brasil, fazer do ambiente um espaço de construção de justiça e não apenas da razão utilitária do mercado (ACSELRAD, 2010, p. 115).

Nas audiências públicas em que estivemos presentes entre os anos de 2016 e 2017 - em três municípios próximos à área do empreendimento, Santana da Boa Vista, Bagé e Pinheiro Machado, e uma audiência na Alergs, em Porto Alegre - uma série de debates sobre a instalação do referido empreendimento em mineração foram realizados. Das audiências que estivemos presentes, além dos componentes da mesa, haviam uma quantidade significativa de participantes por evento, em média 400 pessoas, no qual a maioria do público comparecia para manifestar um posicionamento já formado - a favor ou contra a instalação do empreendimento. Observamos que uma pequena parte foi às audiências se informar e construir um posicionamento acerca dos argumentos favoráveis e contrários à ocorrência de atividade mineradora na região. Após os pronunciamentos dos membros das mesas, as manifestações das plenárias eram na maioria feitas por pessoas com posicionamentos favoráveis e contrários. Ressalta-se que essas audiências, com exceção da realizada na Alergs, foram garantidas por meio de solicitação do Ministério Público.

Nestes espaços, ficaram evidentes as disputas e os diferentes sentidos e significados sobre o que seria o desenvolvimento do bioma Pampa e a atuação da empresa na região por parte da comunidade local, pesquisadores e diferentes instâncias do poder público. Esses diferentes atores se posicionaram, de modo não estático, seja em prol, seja contra e alguns "indecisos" sobre a instalação deste empreendimento de mineração. Estes posicionamentos despertam, consolidam ou remodelam acordos, solidariedades e disputas entre os atores e as múltiplas relações que configuram os conflitos socioambientais, a partir de regimes de justiça distintos, que precisam ser observados de modo a tentar compreender a dimensão socioambiental e territorial, bem como antagonismos sobre a vivência e as formas de convivência com os recursos naturais nos biomas brasileiros na atualidade.

Sobre estes espaços de discussão, podemos analisá-los a partir da discussão de arenas públicas. Cefaï propõe a inserção da varíável cultural para analisar os espaços tidos como arena pública, o que ele entende como um fator importante em um campo de estudos como o da ação coletiva, que antes era dominado, segundo o autor, pelas teorias de mobilização de recursos e processo político. Assim, os direitos de defesa ou reclamação, como mobilização de redes de ativistas e estruturas de oportunidade percebidas, exigem restrições de enquadramentos 
culturais públicos. Desse modo, para Cefaï a dimensão dramática e retórica da ação coletiva deve, portanto, ser repensada em uma teoria de arenas públicas ${ }^{15}$. A ação coletiva, para Cefaï (2009), encontrou seus apoios na "cultura pública" e quando partilhada por seus membros fornece opções para a tomada de partido, atribui lugares nas arenas e indicam as formas mais adequadas de expressão, relacionadas à vida cotidiana.

Assim, observamos que dentre os participantes das audiências e dos debates em diferentes meios de comunicação, como jornais, websites e mídias sociais, a empresa Votorantim Metais e seus representantes trazem uma imagem de um empreendimento com preocupação social e ambiental. Em seu website, há chamadas como "Terra de histórias, solo de valores" ou notícias sobre o projeto de sustentabilidade "Legado das Águas"16, que trazem uma ideia de enraizamento, valorização das características locais e senso de responsabilidade, ao se preocupar com um manancial hídrico, que aliás, é um dos principais geradores de dilemas entre os atores. Também é enfatizado no site e na página do projeto no Facebook o programa educativo operado pela empresa "Parceria Votorantim pela Educação (PVE)". Porém, não constam informações se tais projetos fazem parte (e como) do licenciamento ambiental ${ }^{17}$.

Tanto na apresentação do empreendimento no site quanto nas audiências, os representantes fazem questão de "desmistificar" a preocupação com a contaminação e o assoreamento do rio Camaquã, pois alegam que não haverá descarte de rejeitos no rio e o empreendimento também não irá captar grande volume de água, pois o descarte de rejeitos será feito em pilhas a seco, além de contar com uma estação de tratamento para fazer o reaproveitamento total da água. A promessa é que as áreas de rejeitos receberão revegetação com espécies da região ao final da operação.

15 Para evitar que os quadros de análise recaiam em um possível psicologismo, devem alicerçar a noção de ação coletiva em conexão com as gramáticas da vida pública (CEFAÏ, 2002). A "cultura pública" não é mais somente uma possibilidade de ferramenta analítica, ela préarticula as estruturas de horizonte da vida coletiva, fornecendo materiais de experiência e tornando possível a articulação de uma arena pública na qual estejam disponíveis o que possa ser considerado real e o imaginário, o existente e o possível, o justo e o injusto, o legítimo e o ilegítimo.

16 Trata-se de uma reserva ambiental da empresa no Vale da Ribeira, em São Paulo.

17 O processo de licenciamento ambiental no Brasil é realizado em pelo menos três etapas, a Licença Prévia (LP), Licença de Instalação (LI) e Licença de Operação (LO). Para cada etapa, acompanhada pelo órgão ambiental responsável (a Fepam neste caso, que está atualmente acompanhando a LP), é obrigatório atender a condicionantes estipuladas pelo órgão a partir dos relatórios fornecidos, como EIA-RIMA e Plano Básico Ambiental (PBA), incluindo programas de educação ambiental e de comunicação, entre outros. Dependendo do processo de financiamento do empreendimento, também são obrigatórias atividades de responsabilidade social por parte da empresa. 
Por parte de muitos moradores de Caçapava do Sul, em especial de Minas do Camaquã, e também dos moradores de Santana da Boa Vista, o posicionamento é favorável. Muitos alegam que além dos empregos e de aumentar a arrecadação do município com impostos, alegam não haver registros de problemas de saúde ocasionados pelo impacto dos empreendimentos de mineração que se instalaram ao longo dos anos na região. Entretanto, há diversos relatos sobre a contaminação de mercúrio no Rio Camaquã em 1989 e indícios de contaminação de solo em Maino (2006) e até da água por cobre em volta das Minas do Camaquã por Aldrovandi e Pestana (2012).

Nas audiências públicas que ocorreram nestes municípios, o representante da empresa responsável pela elaboração do EIA/RIMA enfatizou em sua apresentação, uma região, em sua parte socioeconômica, em decréscimo populacional, pois as pessoas buscam alternativas fora da região associando o lugar à falta de trabalho e renda. No argumento, a empresa enfatiza a possibilidade de 450 empregos que a sua implantação iria "levar" à região, fato também que estava presente nas falas dos atores favoráveis ao empreendimento, tais como representantes políticos e comerciantes locais. Muitos remetiam à memória da "vida próspera" do período em que estava instalado o empreendimento anterior, de extração de cobre. Em suas falas, enfatizavam que trabalharam na extração e não haviam sofrido os efeitos na saúde, rebatendo os argumentos contrários ao empreendimento atual, sobre as maneiras que o chumbo seria prejudicial ao corpo humano.

Desse modo, perante o ato e o processo no qual foram promovidas essas audiências públicas, devem ser consideradas as dimensões teórico-políticas a partir dos momentos históricos articulados com a ocorrência do evento. Para Elias (1994), o comportamento individual de cada ator está orientado pela configuração das interdependências, o que se correlaciona com o modo como diferenciam e integram as suas posições. Isto é, a configuração estaria associada aos modos de existência do ser social e às emergências do cotidiano que são constituídas na e pela ambivalência (ELIAS, 1994). Com isso, o entendimento acerca das controvérsias políticas e as posições dos atores devem ser vistas a partir da diversidade cultural, político-ideológica, discursiva e dos conflitos em seu meio político.

Em relação aos atores com posicionamentos contrários, fortalece-se a fala de que há uma disputa por visões de mundo e modos de desenvolvimento para a região, uma voltada ao desenvolvimento com a preservação ambiental aliada à produção de alimentos e outra voltada ao lucro via extração de um minério para exportação, como destaca a fala do representante da Empresa Brasileira de Pesquisa Agropecuária (Embrapa) durante a audiência pública na Alergs. Para o 
representante, o Alto do Camaquã é um local em que o bioma Pampa ainda possui maior área remanescente, vinculada à própria identidade da população da região.

Os possíveis impactos ao meio ambiente não eram apresentados pela empresa gerando diversas perguntas pelos participantes tais como agricultores, pecuaristas, ambientalistas e pesquisadores. Os riscos que a extração de minérios, como o chumbo, ocasiona para a produção pecuária em campos nativos, a criação de abelhas, aos cultivos de feijão estiveram entre as preocupações colocadas por esses grupos em seus tempos de fala. Muitos destes produtores, organizados junto à Associação para o Desenvolvimento sustentável do Alto Camaquã (ADAC) questionavam os 450 empregos amplamente defendidos entre os favoráveis ao empreendimento como impacto positivo, considerando a rede de associações comunitárias, que envolve cerca de 500 famílias - mais de 2.000 pessoas - distribuídas em 25 associações. Assim, estes 450 empregos que a mineradora por ventura possa gerar tendem a inviabilizar a possibilidade de 2.000 empregos que podem ser gerados a partir dos arranjos locais em pecuária familiar. De acordo com estes atores a região, supostamente mais "pobre" economicamente do estado por não ter tido êxito dentro das propostas dos modelos de desenvolvimento (BORBA, 2016) é, também por esta razão, a região mais preservada do bioma Pampa.

Nesse processo se sobressai a relevância do rio Camaquã como um agente na constituição dos modos de ser e viver na região. É constante nas narrativas momentos de sociabilidade das famílias às margens do rio. Desde gurizinho eu pesco no Camaquã conta um pecuarista familiar, em uma das audiências, cuja propriedade está localizada a 5 quilômetros do rio. Todos os finais de ano, o interlocutor visita o rio para pescar peixes tais como dourados e piavas. As histórias, as fotografias e as narrativas das famílias remontam memórias de vivências nas areias e nas águas. Além disso, os inúmeros outros cursos d'água ao longo do rio Camaquã até à Lagoa dos Patos tem em sua extensão diversos povos e comunidades que convivem com esse ecossistema. Por conseguinte, as pessoas se referem à importância de "respeitar o rio" que muda "de uma hora para outra" ficando as partes fundas, rasas e vice-versa. Ou seja, para eles, "respeitar o rio" é considerar que este pode mudar a vazão em poucos minutos e por ser um rio de águas rápidas e indomáveis, que invade as casas que ficam a cerca de 500 metros de distância, é incapaz de ser domesticado por um projeto de mineração.

Há organizações que se destacam nesses debates, dentre elas a União Pela Preservação do Camaquã (UPP), a ADAC e o Comitê dos Povos e Comunidades 
Tradicionais do Pampa ${ }^{18}$. As duas primeiras organizações defendem que os projetos de desenvolvimento da produção local, já em curso (via governo estadual e federal), em especial voltados à ovinocultura, sejam fortalecidos. No caso do comitê alegam que o EIA-RIMA não considera, por exemplo, as diversas características socioculturais intrínsecas aos povos e comunidades tradicionais da região, como as guardiãs e os guardiões das águas, do solo e do patrimônio genético, a manutenção de práticas culturais e espirituais próprias, o cultivo de sistemas de produção agrodiversos e culinária própria que objetivam a soberania e segurança alimentar. Isto é, os(as) representantes destas organizações ressaltam que esses projetos e iniciativas em curso foram ignorados pelo estudo de impacto ambiental e sua credibilidade está comprometida pelo alto potencial de contaminação da atividade mineradora.

Um dos pontos mais enfatizados, os supostos benefícios econômicos, também foram questionados. O representante da Embrapa lembra que "o imposto gerado pela atividade mineradora, a Compensação Financeira pela Exploração de Recursos Minerais (CFEM), equivale a apenas 2\% do faturamento declarado da empresa e que, em uma conta rápida, considerando a produção anunciada pela Votorantim Metais, isso representaria, no máximo, $\mathrm{R} \$ 2$ milhões anuais para Caçapava do Sul e Santana da Boa Vista."19

Alguns pesquisadores e professores de diferentes universidades, como a Unipampa (parceira das ações de educação da empresa), a Universidade Federal do Rio Grande do Sul (UFRGS), Universidade Federal do Rio Grande (FURG) e a Universidade Federal de Pelotas (UFPel) também estiveram presentes neste debate. Com exceção de alguns docentes da primeira universidade, que se posicionaram como favoráveis ao empreendimento, a maioria destes atores reforçaram os questionamentos já mencionados, e apontam também para os possíveis riscos à saúde causados em especial pela extração de chumbo, como dores abdominais em cólica, constipação, impotência sexual, palidez cutânea, anemia, hipertensão arterial, insuficiência renal e neuropatia periférica (LISBOA et al. 2016).

Outra organização presente nos debates foi a ONG Amigos da Terra Brasil. O seu representante anunciou, durante uma audiência em abril, na

18 O Comitê de Povos e Comunidades Tradicionais do Pampa surgiu no I Encontro de Povos e Comunidades Tradicionais do Pampa, em outubro de 2015. O comitê é composto por representantes de diferentes identidades e regiões do bioma, para dar continuidade a esta reflexão coletiva e encaminhar ações de interesse comum, sendo a principal delas a construção de instrumentos políticos de defesa dos seus direitos. Mais informações em: http://comitepampa. com.br/uploads/publicacoes/Livro-Povos-e-Comunidades-Tradicionais-do-Pampa.pdf.

19 Fonte: site Sul21. Disponível pelo link: https://www.sul21.com.br/jornal/com-embate-entregeracao-de-empregos-e-saude-da-populacao-al-discute-mineradora/ 
Alergs, que ao analisar o projeto, era preciso estudar o passado para verificar se era possível confiar no que a Votorantim prometia, questionando assim a credibilidade da empresa. Além deste, na mesma ocasião, um representante do Comitê Gerenciamento da Bacia Hidrográfica do Rio Camaquã comunicou que era contrário ao projeto por receio de contaminação da água do rio, que poderia atingir os municípios que compõem a bacia hidrográfica à jusante do empreendimento.

Alguns docentes da UFRGS, da FURG e da UFPEL focam suas críticas ao EIA-RIMA apresentado pela empresa, dizendo que ele não trazia informações suficientes ao impacto ambiental e área de influência na região, que desconsiderava diversas espécies da fauna e flora nativa e que as informações ali contidas não condizem com a realidade do bioma Pampa. Ao mesmo tempo, nas audiências públicas realizadas nos municípios e na Alergs, alguns docentes da Unipampa (Campus Caçapava do Sul) vinculados a cursos como a Engenharia da Mineração se mostravam favoráveis. Para justificar a sua posição, reivindicavam certa "autoridade científica", um grande entendimento sobre o tema e imputavam às pessoas contrárias ao empreendimento a falta de "intimidade no convívio com a mineração". Entretanto, esses docentes não apresentaram argumentos técnicos ou mesmo dados de pesquisas sobre o tema.

Dentre os deputados do Legislativo do Rio Grande do Sul, há opiniões divergentes, porém os presentes nas audiências, de diferentes correntes políticas, reforçaram a necessidade de preservação do Rio Camaquã como relevante para toda a região, assim como o cuidado com a saúde em função da extração do chumbo ${ }^{20}$. De todo modo, alguns deputados também enfatizaram em seus discursos a possível geração de empregos, prometida pela empresa, que seria direcionada para a população local, desde que seja comprovado que o empreendimento não apresente riscos para a população e o ambiente.

Alguns deputados a favor do empreendimento usaram argumentos semelhantes aos usados pela Votorantim, como a saída das pessoas (abandono) dos municípios - Caçapava do Sul e Santana da Boa Vista - por falta de oportunidade de emprego. Os deputados mencionaram que os moradores desses municípios terão prioridade durante a fase de contratação de mão-de-obra e ficarão com $65 \%$ dos impostos gerados.

O que se percebe nas falas e depoimentos ao longo das audiências é um deslizamento e o uso de uma ambiguidade discursiva dos defensores da instalação

20 Descrição formulada a partir de observação direta em audiência pública realizada em Audiência Pública em abril de 2017 e com aporte de relatos feitos pelo Jornal Sul21 que estão disponíveis em: https://www.sul21.com.br/jornal/com-embate-entre-geracao-de-empregos-e-saude-dapopulacao-al-discute-mineradora/ 
do empreendimento em cada audiência, com determinados dados vindo à tona em uma e em outras audiências não. Exemplo disso é que dados que foram criticados em uma audiência por parte das comunidades e dos grupos contrários foram alterados nas audiências posteriores. Além disso, por exemplo, em duas audiências (em Santana da Boa Vista e na Alergs) a apresentação de PowerPoint foi finalizada no momento em que se apresentaria a relação de impactos, por supostos problemas técnicos.

Conforme Elias (1994), o comportamento individual de cada ator está orientado pela configuração das interdependências, o que se correlaciona com o modo como diferenciam e integram as suas posições. Mesmo que repita a mesma configuração, cada ação no jogo é única e pode variar conforme as estratégias, recursos ou desejos de ação dos grupos envolvidos. Isto é, a configuração estaria associada aos modos de existência do ser social (empreendimento e moradores) e a as emergências do cotidiano que são constituídas na e pela ambivalência (ELIAS, 1994).

No entanto, mesmo em situações permeadas de relações de poder que ditam o "polo" econômico como dotado de uma relevância única, a questão ambiental não é apagada pelo fato do debate sobre os cuidados com o ambiente ser inserido na ordem do dia, mesmo com resultados práticos que sempre podem ser alvo de contestação. Nessas situações, a questão é a disputa por legitimidade das práticas dos grupos que disputam uma posição sobre a forma de uso e convívio com o ambiente. Acselrad traz à tona essa questão:

Disputas de legitimidade instauram-se, concomitantemente, na busca de caracterizar as diferentes práticas como ambientalmente benignas ou danosas. Nessas disputas em que diferentes atores sociais ambientalizam seus discursos, ações coletivas são esboçadas na constituição de conflitos sociais incidentes sobre esses novos objetos, seja questionando os padrões técnicos de apropriação do território e seus recursos, seja contestando a distribuição de poder sobre eles (ACSELRAD, 2010, p. 103).

O "equilíbrio flutuante", muitas vezes reiterado por Elias, é "uma característica do fluxo de cada configuração", pois as configurações possuem aspectos diferentes ou até opostos que convivem e não se excluem. Portanto, além da certeza em relação às contradições que possam ser constatadas pela possível instalação do Projeto Caçapava do Sul em relação ao contexto materializado pelas posições políticas adotadas, também é preciso analisar as incertezas do contexto político e conflituoso no qual a diversidade de atores favoráveis e contrários atuam. Com isso, o entendimento acerca das controvérsias políticas é socialmente construído, seja pela empresa, seja nas organizações e movimentos sociais, 
inclusive em relação as suas posições políticas, a sua diversidade cultural, políticoideológica, discursiva e de conflitos gerados devido aos impactos considerados benéficos ou prejudiciais pela possibilidade da instalação do empreendimento.

Em meio a essas audiências públicas e diante da forma como muitas delas foram reivindicadas e construídas por organizações e movimentos sociais, por exemplo, como o grupo "União pelo Camaquã", que é contra os empreendimentos de mineração nesse bioma. Estes atores que formulam suas denúncias e reivindicações se apoiando em um pano de fundo ambiental e de pertencimento ao local - ou, como dizem, "a nossa terra" - estão redefinindo situações, reelaborando visões do mundo, convicções e identidades sobre o que é viver no bioma Pampa (CEFAI, 2009; 2002). E, ao mesmo tempo, mas sob outro signo, a Votorantim, com o Projeto "Caçapava do Sul”, busca justificar a instalação desse empreendimento, mesmo após uma experiência considerada como falaciosa na silvicultura por várias comunidades da região, pelo discurso de uma perspectiva de crescimento e dinamização econômica de uma região que tem outros diversos povos e comunidades com distintos pressupostos históricos e culturais. Desse modo, a configuração de arenas sociais sobre o tema da mineração proporcionou a atuação de atores que vivem em mundos sociais diversos e se relacionam por meio de colaboração, disputas e conflitos de forma interdependente em meio a processos de transformação, de desintegração, de interseção e de legitimação das suas pautas e interesses (CEFAI, 2002).

\section{CONSIDERAÇÕES FINAIS}

Neste trabalho, procuramos problematizar a implantação de projetos de mineração no bioma Pampa e a possível concentração de danos ambientais sobre as comunidades locais (produtores pecuários, agricultores e comunidades urbanas, rurais, ribeirinhas, indígenas e quilombolas) e os discursos desenvolvimento dos interessados na instalação desse tipo de empreendimento. Compreendemos que a forma de sociabilidade dos atores seja em prol, contra ou indecisos sobre a instalação desses empreendimentos de mineração é uma das maneiras de tentar compreender a dimensão socioambiental e territorial, bem como a configuração dessas formas de disputa e conflito no Brasil na atualidade.

Ao observar as configurações sociais em jogo, procuramos ter uma percepção mais dinâmica e fluída dos processos sociais que envolvem a disputa em torno da instalação do empreendimento na região. Esses processos sociais 
são permeados de estratégias que apesar de demarcadas por uma determinada posição, entretanto, no espaço das audiências públicas passam a realçar a interdependência de diferentes estratégias, acordos, ressignificação de ideias e alianças entre variados atores.

Destacamos que a discussão sobre o projeto da Votorantim Metais na Campanha segue projetando o Escudo Sul-Rio-Grandense como uma das áreas mais ricas em minérios do estado, motivando pedidos de autorização para pesquisa no DNPM (atualmente AMN). Além do projeto da empresa Votorantim, há propostas nas fases de pré-viabilidade e viabilidade econômica, que são: Bujuru, Retiro e Estreito pela Rio Grande Mineração, para minerais pesados na planície costeira do Estado; a Águia Fertilizantes em Três Estradas para extrair fosfatos em carbonatitos; e a Amarillo Gold que quer extrair 6,4 milhões de toneladas de minério de ouro em rochas graníticas no município de Lavras do Sul. O delineamento desses projetos, em vias de intensificação, e as configurações que emergem a partir desse novo contexto constitui um campo de pesquisa importante para as Ciências Sociais, em especial ao trazer o debate sobre os conflitos socioambientais que já estão se projetando e as arenas públicas que têm se formado a partir disso.

Considera-se que o risco socioambiental é um elemento presente em atividades econômicas, em especial em empreendimentos em mineração. Em relação aos seus grandes impactos socioambientais, a mineração gera disputas acerca de bens comuns, como a alteração de paisagem, o patrimônio cultural e histórico, o solo, o ar e a água (elementos bastante abordados pelas organizações e movimentos sociais que observamos). Junto a isso há elementos políticos relacionados aos processos de consulta e participação das comunidades locais sobre a decisão de instalação desses empreendimentos e o respeito à diversidade de arranjos, formas de vida e projetos locais de desenvolvimento, bem como às formas de fiscalização e controle público dos riscos. Entretanto, esses são processos sistematicamente fragilizados no contexto atual por lobistas, investidores, especuladores e mineradoras, bem como por gestores públicos nos governos em níveis federal, estadual e municipal.

O fomento ao desenvolvimento econômico e social sustentável do Pampa tem como características importantes, ao contrário das atividades extrativistas para exportação, assegurar a conservação do bioma, a partir da diversificação da produção rural, da valorização da pecuária com manejo do campo nativo, juntamente com o planejamento regional, o zoneamento ecológico-econômico 
e o respeito aos limites ecossistêmicos são propostas que visam assegurar a conservação da biodiversidade.

Assim, cabe destacar que esse estudo é mais uma forma de contribuir nos estudos acadêmicos e debates políticos sobre como as comunidades locais acometidas pela extração mineral em seu território mobilizam-se diante da instalação de empresas mineradoras, bem como sobre quais os impactos socioambientais na atualidade e os riscos associados a esse tipo de exploração de recursos naturais.

Diante disso, também vislumbramos o desafio futuro de desenvolver uma abordagem teórica e uma lente analítica apropriada e contextualizada para problematizar os conflitos socioambientais relativos à mineração, às comunidades e aos demais grupos sociais que vivem em territórios, como no bioma Pampa, que são territórios mapeados e visados para a instalação de minas de extração mineral e os empreendimentos derivados disso.

\section{REFERÊNCIAS}

ACSELRAD, H. Ambientalização das lutas sociais - o caso do movimento por justiça ambiental. Estudos Avançados, São Paulo, n. 24, v. 68, p.103-119, 2010.

(Org.). Conflitos ambientais no Brasil. Rio de Janeiro: Relume Dumará, 2004.

ACSELRAD, H; DA SILVA, M. G. Rearticulações sociais da terra e do trabalho em áreas de grandes projetos hidrelétricos na Amazônia - o caso de Tucuruí. In: ZHOURI, A. (Org.). As Tensões do lugar hidrelétricas, sujeitos e licenciamento ambiental. Belo Horizonte: EdUFMG, 2011. p. 61-92.

ALDROVANDI, P.; PESTANA, M. H. D. Avaliação da contaminação por metais na área das Minas do Camaquã. Salão da UFRGS, 2012.

ALMEIDA, A. W. B. de. Territórios e territorialidades específicas na Amazônia: entre a "proteção" e o "protecionismo". Cad. CRH, Salvador, v. 25, n. 64, p. 63-72, abr. 2012. Disponível em: <http://www.scielo.br/scielo.php?script=sci_ arttext\&pid=S0103-49792012000100005\&lng=en\&nrm=iso>. Acesso em: 13 out. 2017.

BARRETO, Maria Laura (Ed.). Ensaios sobre a sustentabilidade da mineração no Brasil. Rio de Janeiro: CETEM; MCT, 2001 
BENCKE, G. A. Biodiversidade. In: CHOMENKO, L; BENCKE, G. A. Nosso pampa desconhecido. Porto Alegre: Fundação Zoobotânica do Rio Grande do Sul, 2016, p. 60-75.

BORBA, M. F. S. Desenvolvimento territorial endógeno: O caso do Alto Camaquã. In: WAQUILL, P.; D.; MATTE, A.; NESKE, M. Z.; BORBA, M. F. S. (Org.). Pecuária familiar no Rio Grande do Sul: história, diversidade social e dinâmicas de desenvolvimento. Porto Alegre: Editora da UFRGS, 2016. p. 187214.

BRASIL, Ministério de Minas e Energia. Plano Nacional de Mineração 2030 (PNM - 2030). Brasília, 2010. 178 p.

Ministério do Meio Ambiente. Biomas. 2007. Disponível em: < http:// www.mma.gov.br/biomas/pampa>. Acesso em: 10 jun. 2017.

CANCELIER, J.; KASSOL, W. K. P; NETTO, T. A. A ação do capital no território do pampa In: WIZNIEWSKY, C. R. F.; FOLETO, E. M. (Org.). Olhares sobre o pampa: um território em disputa. Porto Alegre: Evangraf, 2017. p. 169-180.

CEFAÏ, D. Como nos mobilizamos? A contribuição de uma abordagem pragmatista para a sociologia da ação coletiva. Revista Dilemas, v. 2, n. 4, p. 11-48, abr./jun. 2009.

Qu'est-ce qu'une arène publique? In: CEFAÏ, D.; JOSEPH, I. (Org.).

L'héritage du pragmatisme. Conflits d'urbanités et épreuves de civisme. Paris: Editions de l'Aube, 2002. p. 51-82.

COMITÊ DA BACIA HIDROGRÁFICA DO RIO CAMAQUÃ. Bacia Hidrográfica do Rio Camaquã. Disponível em: < http:/ www.comitecamaqua. com/index.php/a-bacia-hidrografica/caracterizacao-geral>. Acessado em: 04 abr 2017.

ELIAS, N. A sociedade dos indivíduos. Rio de Janeiro: Jorge Zahar Ed. 1994.

FERNANDES; V. D.; MIGUEL, L. A. A presença histórica da pecuária familiar na região da Campanha do Rio Grande do Sul (Santana do Livramento, século XIX). In: WAQUILL, P, D.; MATTE, A.; NESKE, M. Z.; BORBA, M. F. S. (Org.). Pecuária Familiar no Rio Grande do Sul: História, Diversidade Social e Dinâmicas de Desenvolvimento. Porto Alegre: Editora UFRGS, 2016. p. 41 - 65.

LEITE LOPES, J. S. Sobre processos de “ambientalização" dos conflitos e sobre dilemas da participação. Horizontes Antropológicos, Porto Alegre, v. 12, n. 25, p. 31-64, jan./jun. 2006. 
LISBOA, L. et al. Proximity of residence to an old mineral storage site in Chile and blood lead levels in children. Cad. Saúde Pública, Rio de Janeiro, v. 32, n. 4, 2016 .

MAINO, J. de M.; WINTER, S. K.; NOVAES, L. E. S. da M. Impactos socioambientais causados pela deposição de rejeitos de mineração na localidade de Minas do Camaquã, Caçapava do Sul/RS, 2006. Disponível em: <http://www.ufpel.edu.br/cic/2006/arquivos/CH_00478.rtf>. Acesso em: 22 out. 2010 .

MALERBA, J. (Org.). Novo Marco Legal da mineração no Brasil: Para quê? Para quem? Rio de Janeiro: FASE, 2012. Disponível em: < http:/ / www.fase.org. br/v2/pagina.php?id=3793>. Acesso em: 13 jan. 2013.

MaZurana, J.; DiAs, J. E.; LAUREAnO, L. C. Povos e comunidades tradicionais da pampa. Porto Alegre: Fundação Luterana de Diaconia, 2016.

MINISTÉRIO DO MEIO AMBIENTE. Pampa. 2007. Disponível em: <http:/ /www.mma.gov.br/biomas/pampa>. Acesso em: 15 ago 2017.

OCMAL. Mapa de conflictos mineros, proyectos y empresas mineras en América Latina. Disponível em: <http://basedatos.conflictosmineros.net/ ocmal_db>.Acesso em: 14 jun. 2017.

PORTAL PLANALTO. Medidas tornam indústria competitiva e vão atrair novos investimentos. 25.07.2017. Por Beto Barata. Disponível em: <http://www2. planalto.gov.br/acompanhe-planalto/noticias/2017/07/medidas-tornamindustria-competitiva-e-vao-atrair-novos-investimentos $>$. Acesso em: 13 out. 2017.

ZHOURI, A.; LASCHEFSKI, K. (Org.). Desenvolvimento e conflitos ambientais. Belo Horizonte: Editora UFMG, 2010. 484 p. 